\title{
The Effectiveness of Local Application of Melatonin in the Original Dermal Film in Experimental Thermal Trauma
}

\author{
M. V. Osikov ${ }^{1,2}, \mathrm{PhD}, \mathrm{ScD} ;$ A. A. Ageeva ${ }^{1 *}$; Yu. I. Ageev ${ }^{1}, \mathrm{PhD}$; A. A. Fedosov ${ }^{3}, \mathrm{PhD}$; \\ K. V. Nikushkina ${ }^{1}, \mathrm{PhD} ;$ Yu. V. Loginova ${ }^{1}$ \\ ${ }^{1}$ South Ural State Medical University, Chelyabinsk, Russia \\ ${ }^{2}$ Chelyabinsk Regional Clinical Hospital, Chelyabinsk, Russia \\ ${ }^{3}$ Russian National Research Medical University named after N.I. Pirogov, Moscow, Russia
}

\begin{abstract}
Background: The development and pathogenetic substantiation of the new agents used for local therapy of thermal trauma (TT) is an urgent problem in medicine. Melatonin (MT) is an endogenous factor of homeostasis regulation with pleiotropic potential. The aim of our study was to assess the morphology, expression of matrix metalloproteinase-9 (MMP-9) and vascular endothelial growth factor (VEGF), indicators of repair, oxidative destruction of lipids in the skin lesion focus in the dynamics of experimental TT under the conditions of using the original dermal film (DF) with MT.

Methods and Results: The experiment was performed on 104 male Wistar rats weighing 200-240 g. For modeling TT II degree according to ICD-10 a relative area of $3.5 \%$ of the body surface, an interscapular region isolated from the surrounding tissues, was immersed in distilled water at $98-99^{\circ} \mathrm{C}$ for $12 \mathrm{sec}$. DF based on sodium carboxymethylcellulose with an area of $12 \mathrm{~cm} 2$ with MT at a concentration of $5 \mathrm{mg} / \mathrm{g}$ was applied daily for five days. The wound area and epithelialization rate were calculated. The content of MMP-9 and VEGF in the burn wound was assessed by an immunohistochemical method. In the homogenate of the burn wound, the content of LPO products was assessed. Morphological and biochemical studies were performed on Days 5, 10 and 20 after TT induction.

With experimental TT from Day 5 to Day 20, the absolute area of the burn wound decreases by $35 \%$, the rate of epithelialization increases, the number of neutrophils in the focus of thermal damage decreases, while the representation of lymphocytes, histiocytes, and fibroblasts increases; the expression of MMP-9 and VEGF increases; predominantly secondary and final LPO products in the heptane phase accumulate, the final products of LPO in the isopropanol phase of the lipid extract. The use of MT in the composition of DF daily for 5 days with experimental TT leads to a decrease in the area of the wound defect (by $46 \%$ of the original area on Day 20), an increase in the rate of its epithelialization, an increase in the content of lymphocytes and fibroblasts in the burn wound on Days 5,10 and 20 of TT, a decrease in the representation of neutrophils and macrophages on Days 5 and 10, as well as an increase in VEGF expression on Days 5 and 10, MMP-9 - on Day 5 and a decrease in MMP-9 expression on Days 10 and 20 of TT. In addition, the use of MT in the composition of DF leads to a decrease in the content of predominantly secondary and end products of LPO in the heptane and isopropanol phases of the burn wound on Days 10 and 20 of TT. Correlation analysis revealed that a decrease in the burn surface area under a local application of MT occurs with an increase in the content of VEGF in the wound area and a decrease in the content of MMP-9 and secondary and final LPO products in the heptane phase and the isopropanol phase. On Day 20, there were direct moderate correlations between the absolute burn surface area, on one hand, and secondary and final LPO products, on the other, in the heptane phase $(\mathrm{R}=0.51, \mathrm{R}=0,68 ; \mathrm{P}<0.05)$ and the isopropanol phase $(\mathrm{R}=0.44, \mathrm{R}=0.46 ; P<0.05)$, respectively.

Conclusion: The results obtained expand the existing understanding of the role of changes in the expression of MMP-9 and VEGF in the pathogenesis of TT. We believe that the repair-stimulating effect of MT in the DF, which we established during TT at the preclinical stage, is associated with the LPO-limiting effect of MT and a change in the expression of MMP-9 and VEGF in the burn wound and is a prerequisite for further study of the mechanism of action and the effectiveness of MT application in clinical conditions in TT. (International Journal of Biomedicine. 2021;11(4):581-589.)
\end{abstract}

Key Words: MMP-9 $\bullet$ VEGF $\bullet$ lipid peroxidation $\bullet$ thermal trauma $\bullet$ melatonin

For citation: Osikov MV, Ageeva AA, Ageev YuI, Fedosov AA, Nikushkina KV, Loginova YuV. The Effectiveness of Local Application of Melatonin in the Original Dermal Film in Experimental Thermal Trauma. International Journal of Biomedicine. 2021;11(4):581-589. doi:10.21103/Article11(4)_OA30 


\section{Abbreviations}

BSA, burn surface area; $\mathbf{C D}$, conjugated dienes; $\mathbf{C T}$, conjugated trienes; DF, dermal films; FRO, free-radical oxidation; GPO, glutathione peroxidase; HPh, heptane phase; IPh, isopropanol phase; KD, ketodienes; LPO, lipid peroxidation; MT, melatonin; MMP, matrix metalloproteinase; MDA, malondialdehyde; SOD, superoxide dismutase; SB, Schiff bases; TT, thermal trauma; VEGF, vascular endothelial growth factor.

\section{Introduction}

A wide range of therapeutic approaches is used for local therapy of small-area thermal trauma (TT). In particular, early surgical necrectomy, which restrains excessive inflammation and infections in the burn wound, and enzymatic debridement of the burn wound. ${ }^{(1)}$ Modern wound dressings are woven or non-woven materials, including hydrogel, gel dressings on a textile basis, hydrocolloid dressings, polyurethane sponge dressings, and calcium alginate dressings, There are wound dressings, on absorbent fabric and non-woven bases, impregnated with solutions of drugs: hemostatic agents, antiseptics, wound healing agents, antioxidants, regenerants of various natures, anti-inflammatory drugs, hemostatic agents, etc. Despite the variety of dressings, the issue of developing drugs for TT local therapy remains topical. To close the burn wound, nylon dressings with collagen, hydrolyzed collagen, or carbon nanotubes can be used, as well as dermal films (DF) based on carboxymethyl cellulose containing various biologically active substances. ${ }^{(2)}$

Adrenaline, thrombin, fibrin, recombinant tissue factor, etc. are used as active components of wound dressings. ${ }^{(3)}$ Hydrogels based on polyvinyl alcohol, chitosan, alginate or polyethylene glycol are widely used when conjugated with zinc oxide, phlorotannins, hyaluronic acid polymyxin B, VEGF, which form a barrier against pathogens and a hydrated environment for wound healing. ${ }^{(4)}$ Fibrin gel is used in patients with TT as a hemostatic and graft fixator and skin substitute..$^{(5)}$ Hydrogels based on hyaluronic acid improve skin regeneration and reduce the area of scar tissue by increasing VEGF secretion, reducing the expression of TGF- $\beta 1{ }^{(6)}$ The skin is the largest organ with intensive FRO processes; oxidative stress during TT is recorded not only in the lesion focus, but also in distant tissues, and therefore antioxidants in TT have shown effectiveness in the coagulation zone (necrosis), limiting cell death in the ischemic zone. ${ }^{(7)}$ In this regard, it is of interest to study the LPO products in the TT focus as markers of the effectiveness of FRO and antioxidant use.

When searching for new therapeutic approaches to TT, special attention is paid to homeostasis regulators of endogenous origin. ${ }^{(8-10)}$ A potential, but theoretically justified, interest in the discussion of promising therapeutic agents for TT is associated with melatonin (MT). MT is one of the most ancient molecules in the evolutionary sense, having been present in living organisms for about 2-3 billion years. It is found in animals, plants, fungi, and prokaryotes, where it originally served as an antioxidant. MT biosynthesis occurs from tryptophan, mainly in the pineal gland. ${ }^{(11)} \mathrm{MT}$ is also synthesized by retinal cells, enterochromaffin cells of the gastrointestinal tract, monocytes, lymphocytes, dendritic and mast cells. ${ }^{(12)}$ Currently, MT is considered as an endogenous factor with multitrophic effects in various cells, including antioxidant, pro- and anti-inflammatory, immunomodulatory, antiapoptogenic, regulating cell proliferation and differentiation, and anti-aging. ${ }^{(13)}$ Mammalian skin has its own melatoninergic system involved in maintaining homeostasis and integrity due to MT synthesis and the presence of specific receptors. Skin cells synthesize MT; its metabolites are found in keratinocytes, melanocytes, and dermal fibroblasts, as well as in melanoma cells. ${ }^{(14)}$ The MT1 receptor is found in keratinocytes and fibroblasts of the skin and hair follicle cells; the MT2 receptor is found mainly in the eccrine glands, blood vessels of the skin, and melanocytes. ${ }^{(15)}$ The ROR $\alpha$ receptor has been identified in epidermal keratinocytes, fibroblasts, and melanocytes. When the skin is damaged, MT accumulates in the epidermis, protecting mitochondria and ensuring the synthesis of ATP.(15) MT regulates the proliferation and differentiation of epidermal cells, the development of hair follicles, the expression of keratin, and involutin in the epidermis. Information was obtained on the radioprotective effect of MT after exposure to X-ray and gamma radiation on the skin in vivo and in cell culture. ${ }^{(16)}$ Considering the above, it is of interest to study the effectiveness of MT local application in the skin TT.

The aim of our study was to assess the morphology, expression of MMP-9 and VEGF, indicators of repair, oxidative destruction of lipids in the skin lesion focus in the dynamics of experimental TT under the conditions of using the original DF with MT.

\section{Methods}

The experiment was performed on 104 male Wistar rats weighing 200-240 g. The animals were randomly divided into 4 groups: Group $1(\mathrm{n}=14)$ included intact control, Group 2 $(\mathrm{n}=30)-$ animals with TT and an aseptic dressing applied to the BSA (TT+ASP); Group $3(\mathrm{n}=30)-$ animals with TT and the DF-matrix and aseptic dressing imposition on the BSA $(\mathrm{TT}+\mathrm{ASP}+\mathrm{DF})$, and Group $4(\mathrm{n}=30)-$ animals with TT in conditions of DF/MT and aseptic dressing application on the $\mathrm{BSA}(\mathrm{TT}+\mathrm{ASP}+\mathrm{DF} / \mathrm{MT})$. The aseptic dressing was changed daily up to 20 days after TT. Since the most common causes of TT are hot liquid and flame, and in two-thirds of patients the area of the burn is less than $10 \%$ of the body surface, ${ }^{(17)}$ for modeling TT II degree according to ICD-10 a relative area of $3.5 \%$ of the body surface, an interscapular region isolated from the surrounding tissues, was immersed in distilled water at 98$99^{\circ} \mathrm{C}$ for $12 \mathrm{sec}$. From the area of the skin in the interscapular region intended for the burn, the hair was clipped and shaved, washed with warm saline and wiped dry. To create TT, a device made of heat-resistant plastic with a hole diameter of $38 \mathrm{~mm}$ was used, into which the animal was placed (Fig.1). The prepared area of the skin interscapular region was aligned with the hole of the device, the animal was fixed. The depth of the burn was verified by morphological methods. For anesthesia, 
the drug Zoletil-100 (tiletamine, zolazepam) (Virbac Sante Animale; France) was used at a dose of $20 \mathrm{mg} / \mathrm{kg}$. DF with an area of $12 \mathrm{~cm}^{2}$ in Groups 3 and 4 was applied immediately after TT, fixing with an aseptic bandage; The TT was dressed daily for 5 days. In preliminary studies, a DF composition was developed based on sodium carboxymethylcellulose (poly-1,4$\beta$-O-carboxymethyl-D-pyranosyl-D-sodium glycopyranose), MT was included at a concentration of $5 \mathrm{mg} / \mathrm{g}$, and it was evaluated by pharmacological and technological parameters: organoleptic indicators (appearance, color, transparency, elasticity, presence of impurities and microcracks), adhesive ability, mechanical tensile strength, and thickness. ${ }^{(18)}$ Group 3 used DF, similar in area and properties, but not containing MT.

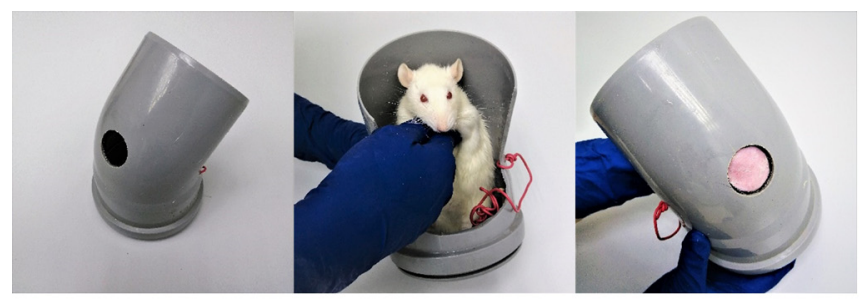

Fig.1. Device for simulation of rat's TT.

A Nikon Coolpix S2800 camera (China) and a Microsoft Office Visio software package were used to calculate the wound area on 24h, Days 5 and 10 after TT by digital planimetry. The epithelialization rate (VS) was calculated by the formula: VS $=\mathrm{S}-\mathrm{Sn} / \mathrm{t}$, where $\mathrm{S}$ is the initial area of the wound before treatment (hereinafter, the area at the previous measurement); $\mathrm{Sn}$ is the area in the subsequent measurement; $\mathrm{t}$ is the number of days between measurements.

The area of the wound (BSA) in subsequent measurements was determined in percent, taking as $100 \%$ the area before treatment, the result was expressed in percent/day. A skin flap was excised along the border of the wound with the capture of an area of intact skin for morphological and immunohistochemical studies. The morphology of the lesion focus was examined on a DMRXA microscope (Leika, Germany) using the ImageScope $M$ computer program (Germany) at $\times 50, \times 200$, and $\times 400$ magnifications. From paraffin blocks, histological sections with a thickness of 5-7 microns were prepared, which were stained with H\&E (Biovitrum, Russia). The depth of skin damage, the reaction of the vascular bed, the presence and composition of the cellular infiltrate, the timing of the appearance of granulation tissue in the wound, and the timing of wound epithelialization were assessed. The following morphometric parameters per $\mathrm{mm}^{2}$ were determined: the number of fibroblasts, neutrophils, histiocytes, and lymphocytes. The content of MMP-9 and VEGF in the burn wound was assessed by an immunohistochemical method using specific polyclonal antibodies to rat MMP-9 (host - rabbit, cat. No. PAA553Ra01 "Cloud-Clone Corp.", China) and polyclonal antibodies to rat VEGF (host - rabbit, cat. No. PAA143Ra01 "Cloud-Clone Corp.", China) and a polymer detection system Rabbit HRP/DAB Detection IHC Detection Kit ("Abcam," Latvia) for detecting antigen-bound rabbit immunoglobulins in tissue sections. Diaminobenzidine was used as a substrate/chromogen for visualization of the polymer complex in the system. We determined the relative area of MMP-9 - positively and VEGF - positively stained structures and determined the integral index of the content of MMP-9 and VEGF as the product of the relative area of the stained structures on the intensity of the color in points. The result was expressed in arbitrary units per $\mathrm{mm}^{2}$ (unit $/ \mathrm{mm}^{2}$ ). In the homogenate of the burn wound, the content of LPO products was assessed. To prepare a $10 \%$ homogenate, the burn wound was excised, $40 \mathrm{mg}$ was washed in chilled buffer, dried, ground and homogenized at $2-4{ }^{\circ} \mathrm{C}$ in $0.4 \mathrm{ml}(1: 10)$ of chilled $0.1 \mathrm{M}$ phosphate buffer $(\mathrm{pH}=7.4)$. LPO products were determined on a spectrophotometer SF-56 ("LOMO - Spectrum," St. Petersburg). ${ }^{(19)}$ The optical density of heptane and isopropanol extracts was measured at $220 \mathrm{~nm}$ (isolated double bonds), 232 $\mathrm{nm}(\mathrm{CD}), 278 \mathrm{~nm}$ (KD and CT), $400 \mathrm{~nm}$ (SB). The relative content of LPO products was expressed in units of oxidation indices (u.o.i.): $\mathrm{E}_{232} / \mathrm{E}_{220}(\mathrm{CD}), \mathrm{E}_{278} / \mathrm{E}_{220}(\mathrm{KD}$ and $\mathrm{CT}$ ), and $\mathrm{E}_{400} / \mathrm{E}_{220}(\mathrm{SB})$. Morphological and biochemical studies were performed on Days 5, 10 and 20 after TT induction.

Statistical analysis was performed using statistical software package SPSS version 19.0 (Armonk, NY: IBM Corp.). The results are presented as median $(\mathrm{Me})$ and and interquartile range (IQR [Q1; Q3]). A non-parametric Kruskal-Wallis test was used for comparisons of median values among groups, followed by post-hoc testing using un-paired Mann-Whitney $\mathrm{U}$ tests. Differences were considered statistically significant at $P<0.01$, taking into account the Bonferroni correction. Spearman's rank correlation coefficient was calculated to measure the strength and direction of the relationship between two variables.

The experiments were performed in accordance with the norms for the humane treatment of animals and approved by the Ethics Committee of the South Ural State Medical University.

\section{Results and Discussion}

When evaluating the parameters of burn wound repair, it was found that in the dynamics of TT on Day 10 of observation, compared with Day 5, the absolute area of the wound defect decreased, which led to an increase in the rate of wound epithelialization and the proportion of decrease in its area (Table 1). On Day 20 of TT, the absolute area of the burn decreased, in comparison with Days 5 and 10; the relative area of the burn decreased compared with Day 5 of observation, which was accompanied by an increase in the rate of wound epithelialization and the proportion of a decrease in its area, compared to Days 5 and 10. The area of the wound defect from Day 5 to Day 20 of experimental TT decreased by 35\% along the median.

On Days 5 and 10, histological examination of the skin determined typical signs of the skin TT: necrosis of the epidermis and dermis layers to the papillary layer, thickening of the connective tissue fibers of the dermis, hyperchromia of the nuclei of the cells of the interstitial tissue (Fig. 2A, 3A). On Day 5, in the perifocal zones in all layers of the skin, we found paretic venous and capillary plethora, small diapedetic hemorrhages, erythroand leukostasis, sludge of erythrocytes; by Day 10, edema of the interstitial tissue led to the accumulation of exudate and the formation of blood clots in the large vessels lumen (Fig. 2A, 3A). 
Table 1.

Influence of MTin the composition of DF on the indicators of wound repair in TT (Me [Q25; Q75])

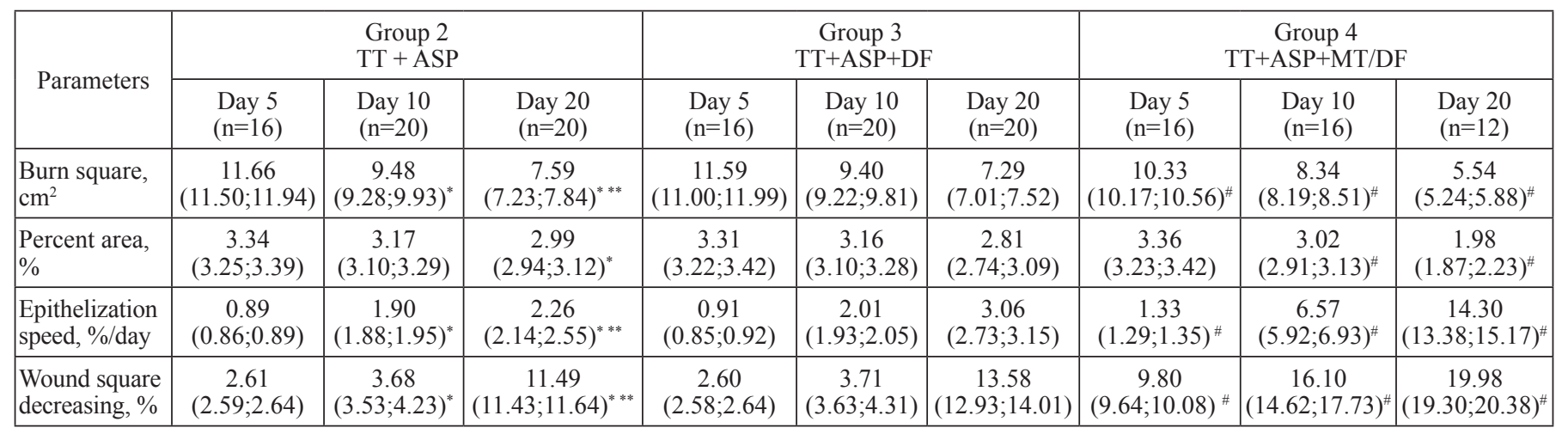

* - significant $(P<0.01)$ differences with Group 2 on Day 5, ** - with Group 2 on Day 10; \# with Group 3.

Cellular infiltration consisted of neutrophils, lymphocytes, and to a lesser extent, macrophages and plasma cells. By Day 10, multiple, diffusely scattered foci of macrophage infiltration were visible. In the middle layers of the dermis there were areas where fibroblasts proliferated, forming bundles and strands, and epithelization was weak, with hyperplasia of cells of the basal layer of the preserved epidermis and proliferation under the scab (Fig. 3A). On Day 20 of TT, an immature scar was determined under the burn scab in the form of compactly packed, dense, little-wrinkled fibers with multiple foci of neutrophilic-lymphocytic and macrophage infiltration (Fig. 4A). Proliferating fibroblasts formed cords and bundles parallel to the skin surface. Newly formed vessels were few in number with endothelial lining and differentiated walls.

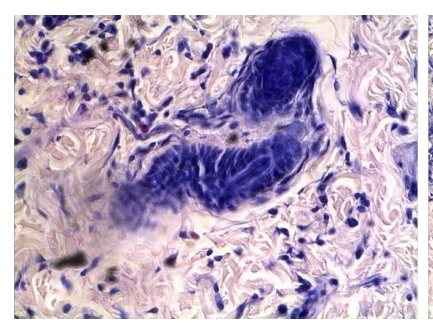

A

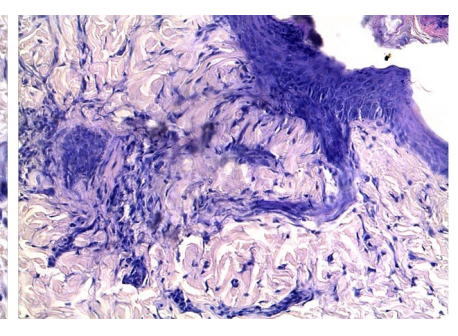

B
Fig. 2. Morphological changes in the dermis of the perifocal zone on Day 5 of TT. H\&E, magnification $\times 400$. A - Group 2 $(T T+A S P):$ stretching and reorientation of hair follicle cell nuclei; $B$ - Group 4 (TT+ASP $+D F / M T)$ : proliferation of cells of the sebaceous glands and hair follicles, the initial phenomena of neoangiogenesis.

A morphometric assessment of the cellular composition of the infiltrate in the TT focus was carried out (Table 2). In the dynamics of TT, the number of neutrophils on Day 10 did not differ from the values on Day 5; on Day 20, it was significantly lower than on Days 5 and 10 . The number of lymphocytes on Day 10 was significantly lower than on Day 5 of TT, and on Day 20, it was significantly higher than on Days 5 and 10. The number of histiocytes and fibroblasts on Day 10 was significantly higher than on Day 5 of TT, and on Day 20 - significantly higher than on Days 5 and 10. On Days 5, 10 , and 20 of TT, VEGF expression significantly increased in the burn wound; on Days 10 and 20 of TT, the expression of
MMP-9 significantly increased also (Table 3 ). In the dynamics of the experiment, the expression of VEGF on Day 10 was higher than on Day 5, on Day 20 - lower than on Day 10; the expression of MMP-9 on Days 10 and 20 was higher than on Day 5 of TT.

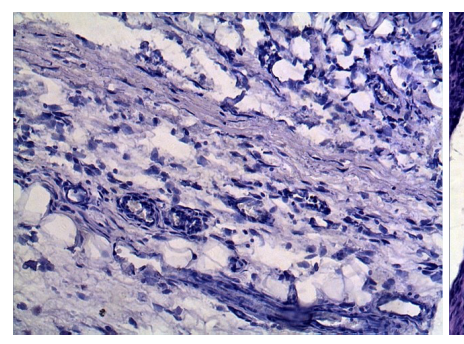

A

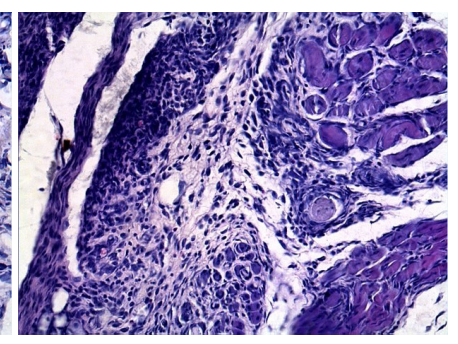

B
Fig. 3. Morphological changes in the perifocal zone in the hypodermis on Day 10 of TT. H\&E, magnification $\times 200$. A - Group 2 (TT $+A S P)$. Focal neutrophilic-lymphocytic infiltration and accumulations of macrophages; $B$ - Group $4(T T+A S P+D F / M T)$. Perifocal zone: in the hypodermis, the proliferation of immature granulation tissue with a large number of cellular elements and the initial phenomena of fibrillogenesis.

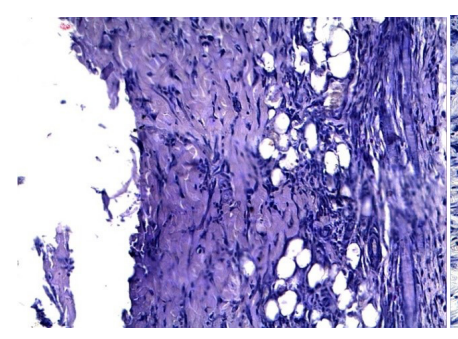

A

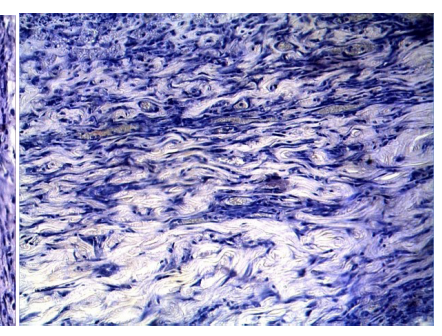

$\mathrm{B}$
Fig. 4. Morphological changes in scar tissue on Day 20 of TT. $H \& E$, magnification $\times 200$. A - Group $2(T T+A S P)$. Densely packed connective tissue fibers of immature scar tissue; $B$ - Group 4 $(T T+A S P+D F / M T)$. Full-blooded newly formed vessels and small foci of macrophage and round-cell infiltration.

In the wound, the content of $\mathrm{KD} / \mathrm{CT}$ and $\mathrm{SB}$ in the $\mathrm{HPh}$ and IPh of the extract increased on Day 5 of TT (Table 4). On Days 10 and 20, in the HPh of the burn wound, the content of $\mathrm{KD} / \mathrm{CT}$ and $\mathrm{SB}$ increased, in the IPh - only SB. In the dynamics of TT, the SB content in the HPh and IPhs was less on Day 10 than on Day 5, and more on Day $20(P<0.01)$ than on Day10. 
Table 2

Influence of MT in the composition of DF on morphometric parameters in the focus of skin damage during TT (Me [Q25; Q75])

\begin{tabular}{|c|c|c|c|c|c|c|c|c|c|}
\hline \multirow{2}{*}{ Parameters } & \multicolumn{3}{|c|}{$\begin{array}{l}\text { Group 2 } \\
\text { TT + ASP }\end{array}$} & \multicolumn{3}{|c|}{$\begin{array}{c}\text { Group } 3 \\
\text { TT+ASP+DF }\end{array}$} & \multicolumn{3}{|c|}{$\begin{array}{c}\text { Group } 4 \\
\mathrm{TT}+\mathrm{ASP}+\mathrm{MT} / \mathrm{DF}\end{array}$} \\
\hline & Day $5(n=43)$ & $\begin{array}{l}\text { Day 10 } \\
(\mathrm{n}=26)\end{array}$ & Day $20(n=26)$ & $\begin{array}{l}\text { Day } 5 \\
(\mathrm{n}=43)\end{array}$ & $\begin{array}{l}\text { Day 10 } \\
(\mathrm{n}=26)\end{array}$ & $\begin{array}{l}\text { Day 20 } \\
(\mathrm{n}=26)\end{array}$ & $\begin{array}{l}\text { Day } 5 \\
(\mathrm{n}=25)\end{array}$ & $\begin{array}{l}\text { Day 10 } \\
(\mathrm{n}=25)\end{array}$ & $\begin{array}{l}\text { Day 20 } \\
(\mathrm{n}=25)\end{array}$ \\
\hline $\begin{array}{l}\text { Neutrophil, } \\
\text { unit/mm² }\end{array}$ & $\mid \begin{array}{c}1184.7 \\
(1080.0 ; 1320.0)\end{array}$ & $\begin{array}{c}1117.7 \\
(1020.0 ; 1240.0)\end{array}$ & $(100.0-160.0)^{* * * *}$ & $\begin{array}{c}1132.6 \\
(1055.0 ; 1302.0)\end{array}$ & $\begin{array}{c}1069.7 \\
(1001.0 ; 1126.0)\end{array}$ & $(104.0 ; 128.0)$ & $\begin{array}{c}384.0 \\
(340.0 ; 420.0)^{\#}\end{array}$ & $\begin{array}{c}373.9 \\
(220.0 ; 20.0)^{\#}\end{array}$ & $\begin{array}{c}110.5 \\
(60.0 ; 160.0)\end{array}$ \\
\hline $\begin{array}{l}\text { Lympho- } \\
\text { cytes, } \\
\text { unit } / \mathrm{mm}^{2}\end{array}$ & $\begin{array}{c}282.3 \\
(220.0 ; 340.0)\end{array}$ & $\begin{array}{c}131.5 \\
(100.0 ; 160.0)^{*}\end{array}$ & $\begin{array}{c}326.9 \\
(260.0 ; 380.0)^{* * *}\end{array}$ & $\begin{array}{c}277.3 \\
(226.0 ; 324.0)\end{array}$ & $\begin{array}{c}135.1 \\
(103.0 ; 157.0)\end{array}$ & $\mid \begin{array}{c}321.4 \\
(257.0 ; 371.0)\end{array}$ & $\begin{array}{c}1187.8 \\
(1040.0 ; 1360.0)^{\#}\end{array}$ & $\begin{array}{c}312.8 \\
(240.0 ; 360.0)^{\#}\end{array}$ & $\begin{array}{c}336.8 \\
(240.0 ; 380.0)\end{array}$ \\
\hline $\begin{array}{l}\text { Fibro- } \\
\text { blasts, } \\
\text { unit } / \mathrm{mm}^{2}\end{array}$ & $\begin{array}{c}140.9 \\
(100.0 ; 160.0)\end{array}$ & $\begin{array}{c}113.1 \\
(80.0 ; 140.0)\end{array}$ & $\begin{array}{c}840.8 \\
(700.0 ; 940.0)^{* * *}\end{array}$ & $\begin{array}{c}144.2 \\
(109.0 ; 162.0)\end{array}$ & $\begin{array}{c}119.4 \\
(85.0 ; 146.0)\end{array}$ & $\begin{array}{c}849.7 \\
(752.0 ; 931.0)\end{array}$ & $\begin{array}{c}175.2 \\
(140.0 ; 220.0)^{\#}\end{array}$ & $\begin{array}{c}335.2 \\
(300.0 ; 380.0)^{\#}\end{array}$ & $\begin{array}{c}973.6 \\
(840.0 ; 1140.0)\end{array}$ \\
\hline $\begin{array}{l}\text { Macro- } \\
\text { phages, } \\
\text { unit } / \mathrm{mm}^{2}\end{array}$ & $\begin{array}{c}366.9 \\
(320.0 ; 420.0)\end{array}$ & $\begin{array}{c}569.2 \\
(440.0 ; 640.0)^{*}\end{array}$ & $\begin{array}{c}667.7 \\
(600.0 ; 740.0)^{* * *}\end{array}$ & $\begin{array}{c}341.8 \\
(310.0 ; 405.0)\end{array}$ & $\begin{array}{c}572.9 \\
(467.0 ; 630.0)\end{array}$ & $\begin{array}{c}612.7 \\
(545.0 ; 668.0)\end{array}$ & $\begin{array}{c}164.8 \\
(120.0 ; 200.0)^{\#}\end{array}$ & $\begin{array}{c}290.4 \\
(220.0 ; 360.0)^{\#}\end{array}$ & $\begin{array}{c}420.8 \\
(340.0 ; 480.0)^{\#}\end{array}$ \\
\hline
\end{tabular}

* - significant $(P<0.01)$ differences with Group 2 on Day 5; ** - with Group 2 on Day 10; \# with Group 3.

Table 3.

Influence of MT in the composition of DF on immunohistochemical parameters in the burn wound (Me [Q25;Q75])

\begin{tabular}{|c|c|c|c|c|c|c|c|c|c|c|}
\hline \multirow{2}{*}{ 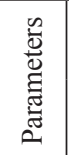 } & \multirow{2}{*}{$\begin{array}{c}\text { Group 1 } \\
\text { (control) } \\
(\mathrm{n}=14)\end{array}$} & \multicolumn{3}{|c|}{$\begin{array}{l}\text { Group } 2 \\
\text { TT + ASP }\end{array}$} & \multicolumn{3}{|c|}{$\begin{array}{c}\text { Group } 3 \\
\mathrm{TT}+\mathrm{ASP}+\mathrm{DF}\end{array}$} & \multicolumn{3}{|c|}{$\begin{array}{c}\text { Group } 4 \\
\mathrm{TT}+\mathrm{ASP}+\mathrm{MT} / \mathrm{DF}\end{array}$} \\
\hline & & $\begin{array}{l}\text { Day } 5 \\
(\mathrm{n}=7)\end{array}$ & $\begin{array}{c}\text { Day } 10 \\
(\mathrm{n}=7)\end{array}$ & $\begin{array}{c}\text { Day } 20 \\
(\mathrm{n}=7)\end{array}$ & $\begin{array}{l}\text { Day } 5 \\
(\mathrm{n}=7)\end{array}$ & $\begin{array}{c}\text { Day } 10 \\
(\mathrm{n}=7)\end{array}$ & $\begin{array}{c}\text { Day } 20 \\
(\mathrm{n}=7)\end{array}$ & $\begin{array}{l}\text { Day } 5 \\
(\mathrm{n}=7)\end{array}$ & $\begin{array}{c}\text { Day } 10 \\
(\mathrm{n}=7)\end{array}$ & $\begin{array}{c}\text { Day } 20 \\
(\mathrm{n}=7)\end{array}$ \\
\hline 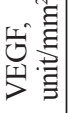 & $\begin{array}{c}3.30 \\
(2.90 ; 3.50)\end{array}$ & $\begin{array}{c}25.05 \\
(23.35 ; 28.30)^{*}\end{array}$ & * $\begin{array}{c}35.50 \\
(33.40 ; 38.10)^{* \#}\end{array}$ & $\begin{array}{c}25.80 \\
(22.30 ; 27.90)^{*}\end{array}$ & $\begin{array}{c}25.40 \\
(22.20 ; 29.30)\end{array}$ & $*(31.50 ; 34.20)^{*}$ & $\left(\begin{array}{c}26.90 \\
(25.80 ; 28.30)^{*}\end{array}\right.$ & $\left(\begin{array}{c}33.00 \\
(30.20 ; 34.90)^{*}\end{array}\right.$ & $\begin{array}{c}45.60 \\
(41.70 ; 49.20)^{*}\end{array}$ & $\begin{array}{c}27.10 \\
(22.50 ; 29.10)^{*}\end{array}$ \\
\hline
\end{tabular}

* - significant $(P<0.01)$ differences with Group 1, \# - with Group 2 on Day 5, \#\# - with Group 2 on Day 10, \& - with Group 3.

The use of MT in the composition of DF during TT led to a statistically significant decrease in the area of the burn wound in absolute values on Days 5, 10, and 20, in relative values on Days 10 and 20 of TT (Table 1). On Days 5, 10, and 20 of observation, the rate of wound epithelialization and the relative decrease in the area of the wound increased. On Day 5 of TT, the absolute area of the BSA decreased by $12.2 \%$; the maximum changes were recorded on Day 20, when the absolute area of the wound defect decreased by $31.6 \%$, and the epithelialization rate increased 4.7 times relative to Group 3. Thus in Group 4, from Day 5 to Day 20 of TT, the absolute area of the BSA decreased by $46 \%$. Morphological examination of the burn wound on Day 5 revealed that along with signs of necrosis of the epidermis and dermis to the papillary layer (changes in the connective tissue characteristic of TT) there was a decrease in the infiltration of the focus by neutrophils and macrophages, the predominance of lymphocytes, young spindle-shaped fibroblasts, a large number of immature newly formed vessels in the form of acellular gaps, and cells of the preserved hair follicles and sebaceous glands participated in epithelialization (Fig.2B). On Day 10, immature granulation tissue with fibroblasts forming bundles and cords, vessels with differentiated walls and endothelial lining were determined in the hypodermis (Fig.3B). In the epidermal layer, at the border of the necrosis focus and intact skin, the proliferation of cells of the basal layer was visible. On Day 20, a completely epithelized young connective tissue scar with fibroblasts, small foci of macrophage, round cell infiltration, and newly formed vessels with differentiated walls were determined (Fig.4B). Young scar tissue was completely epithelialized, with distinct stratification and proliferating cells of the sebaceous glands and hair follicles. Compared to animals of Group 3, in Group 4 the number of neutrophils and histiocytes significantly decreased in the focus of the BSA on Days 5 and 10 of TT, the number of lymphocytes and fibroblasts increased; on Day 20 of TT, the content of histiocytes in the focus of damage decreased, and the number of fibroblasts increased (Table 2).

When evaluating the expression of VEGF and MMP-9 in a burn wound under the conditions of local application of MT, it was found that on Day 5 of the experiment, the expression in the BSA of MMP-9 and VEGF significantly increased; on Day 10, the expression of MMP-9 decreased, VEGF increased; on Day 20 of TT, the expression of MMP-9 decreased, VEGF did not change significantly (Table 3 ). The expression of VEGF on Days 5,10 , and 20, and MMP-9 on Day 5 was significantly higher than in intact animals; the expression of MMP-9 on Days 10 and 20 did not differ from the values in the group of intact animals. 
In Group 4, on Day 5 of TT, in the IPh of the lipid extract of the burn wound, the amount of $\mathrm{KD} / \mathrm{CT}$ and $\mathrm{SB}$ decreased (Table 4). On Day 10 of TT, in the HPh, the amount of KD/ CT decreased, in the IPh - SB decreased also. On Day 20, a decrease in the content of $\mathrm{KD} / \mathrm{CT}$, as well as $\mathrm{SB}$, was recorded in the $\mathrm{HPh}$ and $\mathrm{IPh}$ of the lipid extract of the burn wound. The LPO product content in a burn wound in animals of Group 3 significantly differed from that of intact animals on Days 5 , 10 , and 20 in relation to $\mathrm{KD} / \mathrm{CT}$ in the $\mathrm{HPh}$ of the lipid extract, in relation to SB in the $\mathrm{HPh}$ and $\mathrm{IPh}$ of the lipid extract.

In Group 4, an inverse, significant, weak relationship was found between the absolute BSA and VEGF expression on Days 5 and 10 of the experiment, and a direct moderate relationship with the expression of MMP-9 on Days 10 and 20 of TT (Table 5). The absolute BSA had a direct weak correlation with the content of $\mathrm{KD} / \mathrm{CT}$ in the $\mathrm{HPh}$, and direct moderate correlations with the content of $\mathrm{KD} / \mathrm{CT}$ and $\mathrm{SB}$ in the $\mathrm{IPh}$ on Day 5. On Day 10, we found direct moderate correlations between the absolute BSA and the $\mathrm{KD} / \mathrm{CT}$ content in $\mathrm{HPh}$ and SB in the IPh. On Day 20, there were direct moderate correlations between the absolute $\mathrm{BSA}$, on one hand, and $\mathrm{KD} /$ $\mathrm{CT}$ and $\mathrm{SB}$, on the other, in the HPs and IPh.

So, with TT, well-known morphological patterns and dynamics of the change in the cellular composition during the inflammatory process were recorded: neutrophilic infiltration was most pronounced on Days 5 and 10 and it decreased on Day $20 .{ }^{(20)}$ The maximum representation of lymphocytes and histiocytes, which create the necessary conditions for switching vascular-exudative reactions to proliferative ones, was observed on Day 20 of TT. At the same time, the maximum representation of fibroblasts participating in the synthesis of the extracellular matrix of the connective tissue was recorded.
It is necessary to note the uniformity of the depth of skin damage when using this experimental model of TT with hot water. An increase in the expression of VEGF and MMP-9 in a burn wound is important in TT repair. MMP-9 is involved in the destruction of the extracellular matrix (especially type IV and V collagens), an increase in vascular permeability, chemotaxis of neutrophils, and activation and inactivation of autocoids. It also prepares a springboard for reparative reactions and successful epithelialization, and is inhibited by a tissue inhibitor of proteinases, $\alpha$-1-antichymotrypsin. MMP9 reflects the representation and activity of predominantly neutrophils and macrophages in the TT focus. ${ }^{(21)}$ VEGF is involved not only in the regulation of angiogenesis, but also in the synthesis of collagen and other components of connective tissue, scar formation due to direct and/or indirect activation of fibroblasts, endotheliocytes, neutrophils, macrophages, and mast cells. ${ }^{(22)}$

The reparation in the TT focus is influenced by the redox status of the burn wound. ${ }^{(23)}$ According to other researchers, after TT, the content of LPO products in the plasma, such as MDA, increases and persists for up to 30 days, CD increases slightly on the first day, and then decreases; the levels of reduced glutathione, the activity of SOD, catalase, and total antioxidant capacity of serum decreased. ${ }^{(24)}$

When simulating TT in mice, rats, and pigs, in serum and in a burn wound, the activity of SOD, catalase, GPO, and the total antioxidant activity of serum decrease; the levels of MDA and carbonyl derivatives of proteins increase. ${ }^{(25)} \mathrm{An}$ increase in the LPO product content in the skin TT focus is a result of the activation of FRO under conditions of excessive generation of free radicals and/or a decrease in the activity of antioxidant defense system. Inducers of FRO in TT are NADFH oxidase

Table 4.

Influence of MT in the composition of DF on the content of LPO products in the burn wound homogenate (Me [Q25; Q75])

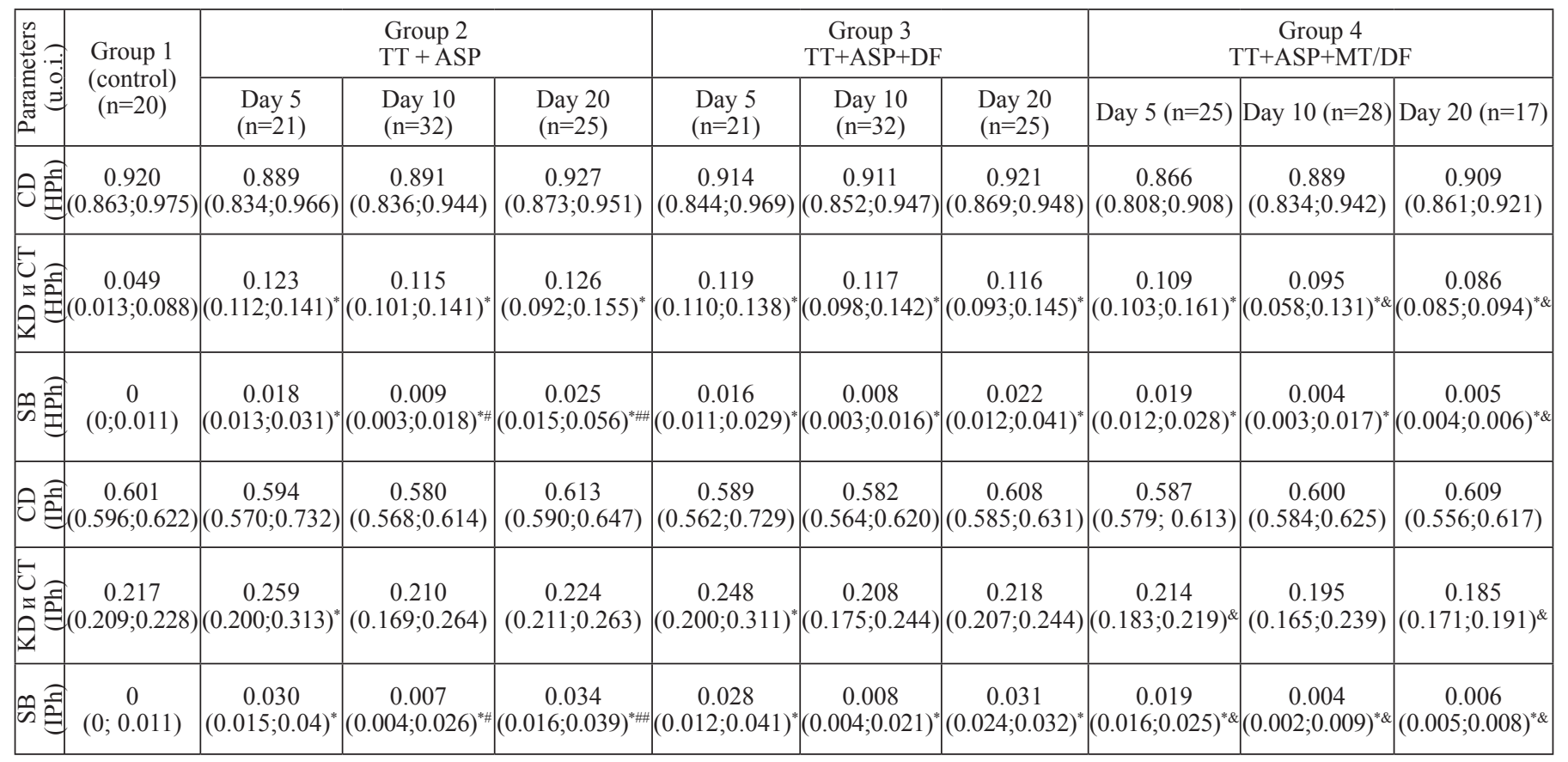

* - significant $(P<0.01)$ differences with Group 1, \# - with Group 2 on Day 5, \#\# - with Group 2 on Day 10, \& - with Group 3. 
and myeloperoxidase of neutrophils, monocytes/macrophages, endotheliocyte xanthine oxidase, monocyte/macrophage NO synthase, and mitochondrial complex I. ${ }^{(26,27)} \mathrm{A}$ decrease in the activity of antioxidant defense components during TT is due to their consumption to inactivate excess free radicals, a decrease in the level of zinc and copper in the body (SOD components), and selenium deficiency (GPO component). ${ }^{(28)}$

\section{Table 5.}

Correlation coefficient ${ }^{\circledR}$ between the absolute BSA and the expression of VEGF and MMP-9 and content of LPO products in the lesion focus during $T T$ in conditions of using DF with MT

\begin{tabular}{|l|c|c|c|}
\hline \multicolumn{1}{|c|}{ Parameters } & $\begin{array}{c}\text { Day 5 } \\
(\mathrm{n}=7)\end{array}$ & $\begin{array}{c}\text { Day 10 } \\
(\mathrm{n}=7)\end{array}$ & $\begin{array}{c}\text { Day 20 } \\
(\mathrm{n}=7)\end{array}$ \\
\hline VEGF, unit $/ \mathrm{mm}^{2}$ & $-0.47^{*}$ & $-0.44^{*}$ & 0.17 \\
\hline MMP-9, unit/mm² & -0.26 & $0.51^{*}$ & $0.57^{*}$ \\
\hline CD (HPh), u.o.i. & 0.21 & 0.18 & 0.19 \\
\hline KD and CT (HPh), u.o.i. & $0.34^{*}$ & $0.52^{*}$ & $0.51^{*}$ \\
\hline SB (HPh), u.o.i. & 0.17 & 0.27 & $0.68^{*}$ \\
\hline CD (IPh), u.o.i. & 0.17 & 0.15 & 0.24 \\
\hline KD and CT (IPh), u.o.i. & $0.68^{*}$ & 0.21 & $0.44^{*}$ \\
\hline SB (IPh), u.o.i. & $0.53^{*}$ & $0.51^{*}$ & $0.46^{*}$ \\
\hline *-P<0.05 & & &
\end{tabular}

The MT effect in the original DF that accelerates the healing of a burn wound, which we discovered, is due to its pleiotropic action. First of all, we believe that the LPO-limiting effect of MT reduces the area of secondary damage during TT, the activation and attraction of neutrophils, monocytes, and lymphocytes to the damage focus. Local application of MT in the composition of DF reduces the infiltration of the lesion focus by neutrophils and histiocytes, and increases the content of lymphocytes and fibroblasts, which helps to reduce the severity of alterative and vascular-exudative reactions in the TT focus with the participation of neutrophils and histiocytes, as well as the early onset of repair with the participation of fibroblasts. The use of MT during TT leads to a decrease in the content of LPO end products in the $\mathrm{HPh}$, and in the primary, secondary, and end products in the IPh of the wound extract. The LPO-limiting effect of MT in a burn wound is associated with a reduction in its area, according to correlation analysis. The pronounced decrease in the level of primary LPO products in the IPh reflects the MTdependent limitation of the early stages of LPO and shielding of phospholipids due to the predominant oxidation of proteins. The antioxidant effect of MT coming from DF into the burn wound through passive diffusion, as well as with the use of glucose and oligopeptide transporters, may be due, first, to the direct absorption of reactive oxygen species (ROS); and, second, to an increase in the synthesis of glutathione; the activity of SOD, catalase, GPO, and hemoxidase-1; and a decrease in the activity of NOS. ${ }^{(14)}$ Finally, the antioxidant effect of MT is realized by maintaining the potential of the mitochondrial membrane and increasing oxidative phosphorylation, production of ATP, not ROS. ${ }^{(29)}$

Modulation of the inflammatory process reactions under the influence of MT may be associated with a decrease in the severity of alteration and vascular-exudative reactions, the production of cytokines, and other autocoids, which will lead to changes not only in the TT focus, but also in the acute phase response in general. Previously, we found that the use of MT in the composition of DF during experimental TT limits the death of lymphocytes in the bloodstream. ${ }^{(30)}$ The direct influence of MT on the production and activity of the factors involved in repair cannot be ruled out. Using correlation analysis, we have demonstrated an association between the VEGF and MMP-9 expression in a burn wound and the BSA under conditions of using DF with MT in TT.

MT in vitro on a culture of brain microvessel endothelial cells reduces the permeability of activated IL-1 $\beta$ cells by inhibiting MMP-9.(31) MT binds MMP-9 excess in COVID-19 - mediated immune response and oral squamous cell carcinoma. ${ }^{(32)}$

MT reduces the MMP-9 overexpression and activity by regulating the signaling pathways NOTCH3/NF- $\mathrm{kB}$, TLR4/ $\mathrm{NF}-\kappa \mathrm{B} \cdot{ }^{(33)}$ Information on the effect of MT on VEGF synthesis and expression is ambiguous: MT inhibits VEGF synthesis in human neuroblastoma cells and prostate cancer by blocking stabilization of the STAT3 and HIF-1 $\alpha$ complex. ${ }^{(34)}$ Recent data indicate that MT has a regulatory effect on angiogenesis, depending on the dose (concentration in tissues) and the initial state of the tissue. During bone repair, skin healing, ulcerative defects of the gastric mucosa, and myocardial ischemia, the use of MT enhances the angiogenic potential of mesenchymal stem cells due to the synthesis of VEGF along the Erk1/2 pathway and stimulation of the synthesis of platelet growth factor. $^{(34,35)}$

\section{Conclusion}

With experimental TT from Day 5 to Day 20, the absolute area of the burn wound decreases by $35 \%$, the rate of epithelialization increases, the number of neutrophils in the focus of thermal damage decreases, while the representation of lymphocytes, histiocytes, and fibroblasts increases; the expression of MMP-9 and VEGF increases; predominantly secondary and final LPO products in the heptane phase accumulate, the final products of LPO in the IPh of the lipid extract. The use of MT in the composition of DF daily for 5 days with experimental TT leads to a decrease in the area of the wound defect (by $46 \%$ of the original area on Day 20), an increase in the rate of its epithelialization, an increase in the content of lymphocytes and fibroblasts in the burn wound on Days 5, 10 and 20 of TT, a decrease in the representation of neutrophils and macrophages on Days 5 and 10, as well as an increase in VEGF expression on Days 5 and 10, MMP-9 - on Day 5 and a decrease in MMP-9 expression on Days 10 and 20 of TT. In addition, the use of MT in the composition of DF leads to a decrease in the content of predominantly secondary and end products of LPO in the HPh and IPh of the burn wound on Days 10 and 20 of TT. Correlation analysis revealed that a decrease in the BSA under a local application of MT occurs with an increase in the content of VEGF in the wound area and a decrease in the content of MMP-9 and secondary and final LPO products in the $\mathrm{HPh}$ and $\mathrm{IPh}$. The results obtained expand the 
existing understanding of the role of changes in the expression of MMP-9 and VEGF in the pathogenesis of TT, and serve as a prerequisite for further research studies. We believe that the repair-stimulating effect of MT in the DF, which we established during TT at the preclinical stage, is associated with LPOlimiting effect of MT and a change in the expression of MMP-9 and VEGF in the burn wound and is a prerequisite for further study of the mechanism of action and the effectiveness of MT application in clinical conditions in TT.

\section{Sources of Funding}

This study was supported by the Russian Foundation for Basic Research and the Chelyabinsk Region within the framework of the scientific project No. 20-415-740016.

\section{Conflict of Interests}

The authors declare that they have no conflicts of interest.

\section{References}

1. Hirche C, Citterio A, Hoeksema H, Koller J, Lehner M, Martinez JR, Monstrey S, Murray A, Plock JA, Sander F, Schulz A, Ziegler B, Kneser U. Eschar removal by bromelain based enzymatic debridement $\left(\right.$ Nexobrid $\left.^{\mathbb{B}}\right)$ in burns: An European consensus. Burns. 2017 Dec;43(8):1640-1653. doi: 10.1016/j.burns.2017.07.025.

2. Serebrakian AT, Pickrell BB, Varon DE, Mohamadi A, Grinstaff MW, Rodriguez EK, Nazarian A, Halvorson EG, Sinha I. Meta-analysis and Systematic Review of Skin Graft Donor-site Dressings with Future Guidelines. Plast Reconstr Surg Glob Open. 2018 Sep 24;6(9):e1928. doi: 10.1097/ GOX.0000000000001928.

3. Kim Y, Kym D, Cho YS, Yoon J, Yim H, Hur J, Chun W. Use of Fibrin Sealant for Split-Thickness Skin Grafts in Patients with Hand Burns: A Prospective Cohort Study. Adv Skin Wound Care. 2018 Dec;31(12):551-555. doi: 10.1097/01. ASW.0000547413.61758.27.

4. Huang J, Ren J, Chen G, Li Z, Liu Y, Wang G, Wu X. Tunable sequential drug delivery system based on chitosan/ hyaluronic acid hydrogels and PLGA microspheres for management of non-healing infected wounds. Mater Sci Eng C Mater Biol Appl. 2018 Aug 1;89:213-222. doi: 10.1016/j. msec.2018.04.009.

5. Mullens CL, Messa CA 4th, Kozak GM, Rhemtulla IA, Fischer JP. To Glue or Not to Glue? Analysis of Fibrin Glue for Split-thickness Skin Graft Fixation. Plast Reconstr Surg Glob Open. 2019 May 16;7(5):e2187. doi: 10.1097/ GOX.0000000000002187.

6. Hong L, Shen M, Fang J, Wang Y, Bao Z, Bu S, Zhu Y. Hyaluronic acid (HA)-based hydrogels for full-thickness wound repairing and skin regeneration. J Mater Sci Mater Med. 2018 Sep 8;29(9):150. doi: 10.1007/s10856-018-6158-x. 7. Mitran MI, Nicolae I, Tampa M, Mitran CI, Caruntu C, Sarbu MI, Ene CD, Matei C, Georgescu SR, Popa MI. Reactive Carbonyl Species as Potential Pro-Oxidant Factors Involved in Lichen Planus Pathogenesis. Metabolites. 2019 Oct 3;9(10):213. doi: 10.3390/metabo9100213.

8. Osikov MV, Gizinger OA, Ogneva OI. [Mechanism of the influence of melatonin on the immune status in experimental desynchronosis under led lighting]. Medical Immunology. 2015.17(6):517-524. [Article in Russian].

9. Osikov MV, Telesheva LF, Ageev YuI. [Antioxidant effect of erythropoetin in experimental chronic renal failure]. Bull Exp Biol Med. 2015;160(8):162-165. [Article in Russian].

10. Osikov MV, Makarov EV, Krivokhizhina LV. Hemostasiological effects of $\alpha 1$-acid glycoprotein in experimental septic peritonitis. Bull Exp Biol Med. 2007;144(8):143-145. [Article in Russian].

11. Zhao D, Yu Y, Shen Y, Liu Q, Zhao Z, Sharma R, Reiter RJ. Melatonin Synthesis and Function: Evolutionary History in Animals and Plants. Front Endocrinol (Lausanne). 2019 Apr 17;10:249. doi: 10.3389/fendo.2019.00249.

12. Markus RP, Fernandes PA, Kinker GS, da Silveira Cruz-Machado S, Marçola M. Immune-pineal axis - acute inflammatory responses coordinate melatonin synthesis by pinealocytes and phagocytes. Br J Pharmacol. 2018 Aug;175(16):3239-3250. doi: 10.1111/bph.14083.

13. Varoni EM, Soru C, Pluchino R, Intra C, Iriti M. The Impact of Melatonin in Research. Molecules. 2016 Feb 20;21(2):240. doi: 10.3390/molecules21020240.

14. Slominski AT, Kim TK, Kleszczyński K, Semak I, Janjetovic Z, Sweatman T, Skobowiat C, Steketee JD, Lin Z, Postlethwaite A, Li W, Reiter RJ, Tobin DJ. Characterization of serotonin and $\mathrm{N}$-acetylserotonin systems in the human epidermis and skin cells. J Pineal Res. 2020 Mar;68(2):e12626. doi: $10.1111 /$ jpi.12626.

15. Rusanova I, Martínez-Ruiz L, Florido J, RodríguezSantana C, Guerra-Librero A, Acuña-Castroviejo D, Escames G. Protective Effects of Melatonin on the Skin: Future Perspectives. Int J Mol Sci. 2019 Oct 8;20(19):4948. doi: 10.3390/ijms20194948.

16. Shabeeb D, Najafi M, Musa AE, Keshavarz M, Shirazi A, Hassanzadeh G, Hadian MR, Samandari H. Biochemical and Histopathological Evaluation of the Radioprotective Effects of Melatonin Against Gamma Ray-Induced Skin Damage. Curr Radiopharm. 2019;12(1):72-81. doi: 10.2174/18744710 12666181120163250.

17. Li H, Yao Z, Tan J, Zhou J, LiY, Wu J, Luo G. Epidemiology and outcome analysis of 6325 burn patients: a five-year retrospective study in a major burn center in Southwest China. Sci Rep. 2017 Apr 6;7:46066. doi: 10.1038/srep46066.

18. Ageeva AA, Osikov MV, Simonjan EV, Toporec TA, Potehina EA, authors. Federal State Budgetary Educational Institution of Higher Education "South Ural State Medical University" of the Ministry of Health of the Russian Federation, patent holder. "Remedy in the form of a medicinal film containing melatonin for the treatment of thermal injury." Patent \#2 751048 07.07.2021. [In Russian].

19. Volchegorsky IA, Nalimov AG, Yarovinsky VG. [Comparison of different approaches to the determination of LPO products in heptane-isopropanol blood extracts]. Questions of Medical Chemistry. 1989;(35)1:127-131.[Article in Russian].

20. Davenport L, Dobson G, Letson H. A new model for standardising and treating thermal injury in the rat. MethodsX. 2019 Sep 12;6:2021-2027. doi: 10.1016/j.mex.2019.09.006.

21. Nagy B, Szélig L, Rendeki S, Loibl C, Rézmán B, Lantos J, Bogár L, Csontos C. Dynamic changes of matrix

*Corresponding author: Anna A. Ageeva, PhD. Department of Pathological Physiology, South Ural State Medical University, Chelyabinsk, Russia. E-mail: anne.ageeva.r@yandex.ru 
metalloproteinase 9 and tissue inhibitor of metalloproteinase 1 after burn injury. J Crit Care. 2015 Feb;30(1):162-6. doi: 10.1016/j.jcrc.2014.07.008.

22. Wilgus TA. Vascular Endothelial Growth Factor and Cutaneous Scarring. Adv Wound Care (New Rochelle). 2019 Dec 1;8(12):671-678. doi: 10.1089/wound.2018.0796.

23. de Aquino PEA, de Souza TFG, Santos FA, Viana AFSC, Louchard BO, Leal LKAM, Rocha TM, Evangelista JSAM, de Aquino NC, de Alencar NMN, Silveira EDR, Viana GSB. The Wound Healing Property of $N$-Methyl-(2S,4R)-trans-4Hydroxy-L-Proline from Sideroxylon obtusifolium is Related to its Anti-Inflammatory and Antioxidant Actions. J Evid Based Integr Med. 2019 Jan-Dec;24:2515690X19865166. doi: $10.1177 / 2515690 X 19865166$.

24. Qin FJ, Hu XH, Chen Z, Chen X, Shen YM. Protective effects of tiopronin against oxidative stress in severely burned patients. Drug Des Devel Ther. 2019 Aug 13;13:2827-2832. doi: 10.2147/DDDT.S215927.

25. He F, Jiao H, Tian Y, Zhao L, Liao X, Fan Z, Liu B. Facile and large-scale synthesis of curcumin/PVA hydrogel: effectively kill bacteria and accelerate cutaneous wound healing in the rat. J Biomater Sci Polym Ed. 2018 Mar;29(4):325-343. doi: $10.1080 / 09205063.2017 .1417002$.

26. Olczyk P, Komosinska-Vassev K, Ramos P, Mencner Ł, Olczyk K, Pilawa B. Application of Numerical Analysis of the Shape of Electron Paramagnetic Resonance Spectra for Determination of the Number of Different Groups of Radicals in the Burn Wounds. Oxid Med Cell Longev. 2017;2017:4683102. doi: 10.1155/2017/4683102.

27. Nakazawa H, Ikeda K, Shinozaki S, Yasuhara S, Yu YM, Martyn JAJ, Tompkins RG, Yorozu T, Inoue S, Kaneki M. Coenzyme Q10 protects against burn-induced mitochondrial dysfunction and impaired insulin signaling in mouse skeletal muscle. FEBS Open Bio. 2019 Jan 19;9(2):348-363. doi: 10.1002/2211-5463.12580.

28. Lee YH, Bang ES, Lee JH, Lee JD, Kang DR, Hong J, Lee JM. Serum Concentrations of Trace Elements Zinc, Copper,
Selenium, and Manganese in Critically Ill Patients. Biol Trace Elem Res. 2019 Apr;188(2):316-325. doi: 10.1007/s12011018-1429-4.

29. Reiter RJ, Rosales-Corral S, Tan DX, Jou MJ, Galano A, Xu B. Melatonin as a mitochondria-targeted antioxidant: one of evolution's best ideas. Cell Mol Life Sci. 2017 Nov;74(21):3863-3881. doi: 10.1007/s00018-017-2609-7.

30. Osikov MV, Simonyan EV, Ageeva AA, Ageev YuI. [Melatonin in the dermal film limits the blood lymphocyte death in experimental thermal trauma]. Medical Immunology. 2021;23(2):389-394. [Article in Russian]

31. Alluri H, Wilson RL, Anasooya Shaji C, Wiggins-Dohlvik K, Patel S, Liu Y, Peng X, Beeram MR, Davis ML, Huang JH, Tharakan B. Melatonin Preserves Blood-Brain Barrier Integrity and Permeability via Matrix Metalloproteinase-9 Inhibition. PLoS One. 2016 May 6;11(5):e0154427. doi: 10.1371/journal.pone.0154427.

32. Hazra S, Chaudhuri AG, Tiwary BK, Chakrabarti N. Matrix metallopeptidase 9 as a host protein target of chloroquine and melatonin for immunoregulation in COVID-19: A networkbased meta-analysis. Life Sci. 2020 Sep 15;257:118096. doi: 10.1016/j.lfs.2020.118096.

33. Qin W, Li J, Zhu R, Gao S, Fan J, Xia M, Zhao RC, Zhang J. Melatonin protects blood-brain barrier integrity and permeability by inhibiting matrix metalloproteinase-9 via the NOTCH3/NF-kB pathway. Aging (Albany NY). 2019 Dec 7;11(23):11391-11415. doi: 10.18632/aging.102537.

34. Rahbarghazi A, Siahkouhian M, Rahbarghazi R, Ahmadi M, Bolboli L, Keyhanmanesh R, Mahdipour M, Rajabi H. Role of melatonin in the angiogenesis potential; highlights on the cardiovascular disease. J Inflamm (Lond). $2021 \mathrm{Feb}$ 2;18(1):4. doi: 10.1186/s12950-021-00269-5.

35. Lee JH, Yoon YM, Han YS, Jung SK, Lee SH. Melatonin protects mesenchymal stem cells from autophagy-mediated death under ischaemic ER-stress conditions by increasing prion protein expression. Cell Prolif. 2019 Mar;52(2):e12545. doi: $10.1111 /$ cpr. 12545 . 